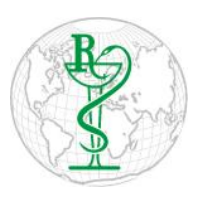

INDO GLOBAL JOURNAL OF

PHARMACEUTICAL SCIENCES

ISSN 2249- 1023

\title{
A Stability Indicating Method Development of Atorvastatin Calcium and Amlodipine Besylate in Combined Tablet Dosage Forms by RP- HPLC
}

\author{
A. Indira ${ }^{1 *}$, N.Y. Sreedhar ${ }^{2}$ \\ ${ }^{1}$ Department of Chemistry, AG \& SG Degree College, Vuyyuru, Krishna District, Andhra Pradesh, India-521165 \\ ${ }^{2}$ SV University, Tirupati, Andhra Pradesh India-517101
}

Address for Correspondence: A. Indira, avisaindira111@gmail.com

\begin{abstract}
Received:
28.02.2019

Accepted:

13.12.2019

Published:

05.12.2020

Keywords

Atorvastatin;

Amlodipine;

HPLC; Stability.
\end{abstract}

ABSTRACT: A new stability indicating RP-HPLC method was developed for simultaneous estimation of atorvastatin and amlodipine in combined tablet formulations. Chromatography was carried out on a Kromasil C18 HPLC Column $(250 \times 4.6 \mathrm{~mm} ; 5 \mu \mathrm{m})$ eluting with a mobile phase consisting of a $60: 40 \mathrm{v} / \mathrm{v}$ mixture of $0.1 \%$ orthophosphoric acid in water and acetonitrile $(\mathrm{ACN})$ at a flow rate of $1.0 \mathrm{~mL} /$ minute. The detection wavelength was set at $240 \mathrm{~nm}$. Accuracy was assessed by using standard addition method. The developed HPLC method was validated with respect to precision, specificity, accuracy, linearity and robustness. Forced degradation studies on the formulation were conducted by adopting the proposed method to assess the stability of the analytes under acid, base, peroxide, thermal and photolytic conditions and suitability of the method to resolve the degradation products. () 2020 iGlobal Research and Publishing Foundation. All rights reserved.

Cite this article as: Indira, A.; Sreedhar, N.Y. A stability indicating method development of atorvastatin calcium and amlodipine besylate in combined tablet dosage forms by RP-HPLC. Indo Global J. Pharm. Sci., 2020; 10(1): 79-84. DOI: http://doi.org/10.35652/IGJPS.2020.10111.

\section{INTRODUCTION}

Atorvastatin Calcium is calcium salt of $(\beta R, 8 R)-2-(4-$ fluorophenyl)- $\alpha, \delta$-dihydroxy-5-(1-methylethyl)-3-phenyl-4-

[(phenylamino)carbonyl]-1H-pyrrole-1-heptanoic acid trihydrate and Atorvastatin is used to reduce the risk of cardiovascular disorders and is in a class of medications called HMG-CoA reductase inhibitors (statins). Amlodipine Besilate is 3-ethyl 5-methyl (4RS)-2-[(2aminoethoxy)methyl]-4-(2-chlorophenyl)-6-methyl-1,4dihydropyridine-3,5-dicarboxylate benzene sulphonate.

Amlodipine is a popular antihypertensive drug belonging to the group of drugs called dihydropyridine calcium channel blockers.The structure of Atorvastatin and Amlodipine[1] are shown in Fig 1.

Hypertension and associated disorders are highly affecting people worldwide due to several reasons. One major cause is due to hyperlipidemic process, where the unwanted fat gets deposited in the coronary blood vessels present in heart and other vasculature. Hence, several deaths have been occurred due to cardiovascular problems. Thus, the pharmaceutical companies have come up with a combination for both categories of drugs to have in a single formulation such that the hypertension associated with hyper lipidimic condition could be treated and the life span can be improved. Several methods were performed for the analysis of these drugs using individual spectroscopic [2-3] and chromatographic techniques [4-6]. There are also few reports available for the method development of the combination of these drugs. However there are few reports for stability indicating method available for the combination of Atorvastatin and Amlodipine drugs [7-9]. The stability of the combination plays an important role in the health of the individuals, since the degraded products due to less stability could be a major risk of toxicity. Hence identifying a method for this combination including stability would be an important analytical prospect. The main aim of present investigation is to develop a validated RP-HPLC method for the analysis of stability aspects of 
Indo Global Journal of Pharmaceutical Sciences, 2020; 10(1): 79-84

atorvastatin and amlodipine in bulk and pharmaceutical dosage forms.
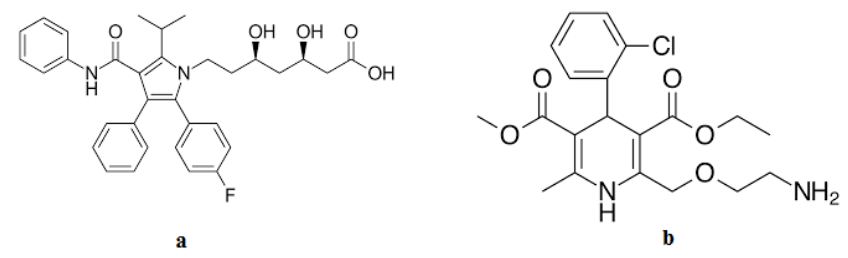

Fig. 1: Structure of a) Atorvastatin b) Amlodipine

\section{MATERIALS AND METHODS}

Chemicals and Reagents

Amlodipine besylate and Atorvastatin calcium were obtained as gift samples from Mylan Laboratories Ltd., Hyderabad. Methanol AR grade, $\mathrm{HCl}, \mathrm{NaOH}$ and hydrogen peroxide were procured from SD Fine Chem limited, Mumbai. HPLC water and Methanol were purchased from Merck specialties private limited, Mumbai. The combination tablets AMTR 10 were purchased from local pharmacy.

\section{Instrumentation}

Axis Ag N 204-PO digital balance, Elico LI 120 pH meter, 1.5LH Ultrasonic bath sonicator, LAB INDIA $2000^{+}$double beam UV-Visible spectrophotometer, with wide Range Photodiode, . Agilent 1120 compact LC system with Kromasil 100-5C18 column (250 x $4.6 \mathrm{~mm})$ using Ezchrome Elite Compact software.

\section{Selection of Mobile Phase}

The standard solutions containing Atorvastatin and Amlodipine besylate were injected into the HPLC system and run in different solvent systems. This mobile phase system was tried with different proportions and using different flow rates. The optimal composition of mobile phase was obtained in the ratio of Phosphate buffer ( $\mathrm{pH} 7)$ : Acetonitrile (50:50).

\section{Method Development}

\section{Preparation of Mobile Phase}

Mobile phase was prepared by mixing Phosphate buffer $(\mathrm{pH}$

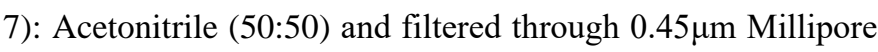
membrane filter and degassed for $15 \mathrm{~min}$ before use.

\section{Preparation of Standard Stock Solution}

The separate stock solutions of Atorvastatin and Amlodipine besylate were prepared by accurately weighing $25 \mathrm{mg}$ each into a separate $25 \mathrm{ml}$ volumetric flasks $\mathrm{A}$ and $\mathrm{B}$ and made up to the volume with mobile phase to get $1000 \mu \mathrm{g} / \mathrm{ml}$ respectively. From the above standard stock solutions $1 \mathrm{~mL}$ from volumetric flask A and $1 \mathrm{ml}$ from volumetric flask B was transferred to a $10 \mathrm{ml}$ volumetric flask and made up to the volume with same mobile phase to get $100 \mu \mathrm{g} / \mathrm{ml}$ and $100 \mu \mathrm{g} / \mathrm{ml}$ of Atorvastatin and Amlodipine besylate (Working stock solution).The stock solution was filtered through $0.45 \mathrm{~mm}$ Millipore membrane filter, sonicated and degassed.

\section{Selection of Analytical Wavelength}

Each solution was scanned using double beam UV visible spectrophotometer between the range of $200-400 \mathrm{~nm}$ and their spectra were recorded. Atorvastatin and, Amlodipine besylate $259 \mathrm{~nm}$ was selected as analytical wavelength for Multicomponent analysis using HPLC method.

\section{Optimized Chromatographic Conditions}

Mobile phase consisting of Phosphate buffer: Acetonitrile $(50: 50 \mathrm{v} / \mathrm{v})$ was used in isocratic mode. The flow rate was maintained at $1 \mathrm{ml} / \mathrm{min}$ and the injection volume was $20 \mu \mathrm{L}$. UV detection was performed at $259 \mathrm{~nm}$ and the separation was achieved at ambient temperature.

\section{Selection of Analytical Concentration Range}

Appropriate aliquots ranging from $1.0 \mathrm{~mL}$ to $5.0 \mathrm{~mL}$ and 0.5 to $2.5 \mathrm{~mL}$ were pipetted out from the working stock solution of $1000 \mu \mathrm{g} / \mathrm{mL}$ of Atorvastatin and $1000 \mu \mathrm{g} / \mathrm{mL}$ of Amlodipine Besylate respectively in to a series of $10 \mathrm{ml}$ volumetric flasks. The volume was made up to the mark with the mobile phase to get a set of solutions having the concentration range, ranging from $100-500 \mu \mathrm{g} / \mathrm{ml}$ of Atorvastatin and $50-250 \mu \mathrm{g} / \mathrm{ml}$ of Amlodipine besylate. Triplicate dilutions of each of the above mentioned concentrations were prepared and each concentration was injected into the HPLC system. Both the drugs follow the Beer's Lambert's law in the concentration range of 100$500 \mu \mathrm{g} / \mathrm{ml}$ of Atorvastatin and $50-250 \mu \mathrm{g} / \mathrm{ml}$ of Amlodipine Besylate .

\section{Method Validation}

The method was validated according to ICH Q2 B guidelines for validation of analytical procedures in order to determine system suitability, linearity, sensitivity, precision, accuracy and robustness for the analytes.

\section{Linearity and Range}

The linearity of the method was determined in concentration range of $100-500 \mu \mathrm{g} / \mathrm{ml}$ for Atorvastatin and $50-250 \mu \mathrm{g} / \mathrm{ml}$ for, Amlodipine besylate. Each solution was injected in triplicate. Chromatograms representing linearity were shown in fig 2. The slope, intercept was reported as required by ICH which were given in Table 1. 
Indo Global Journal of Pharmaceutical Sciences, 2020; 10(1): 79-84

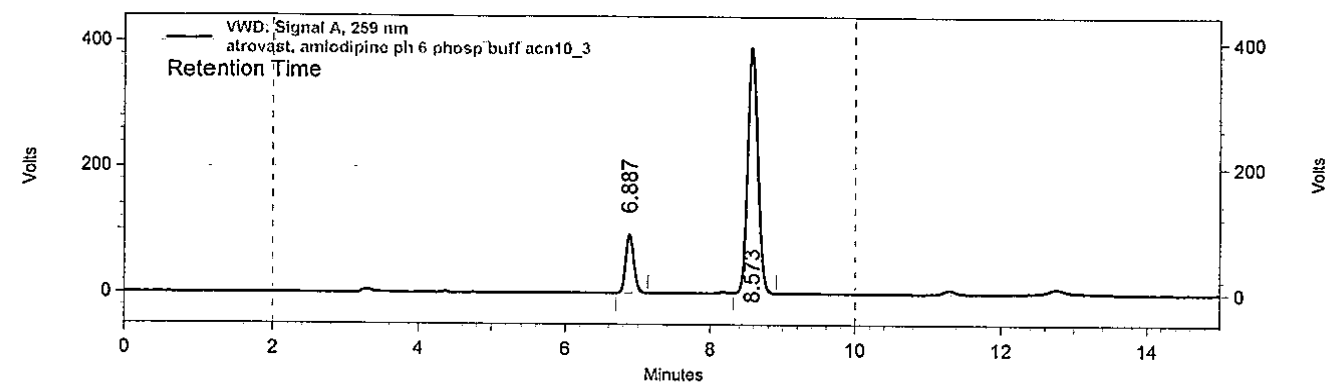

Fig. 2: RP-HPLC Chromatogram of combination Linearity

Table 1: Linearity Data of Atorvastatin and Amlodipine besylate at 259nm

\begin{tabular}{|c|c|c|c|c|c|}
\hline \multicolumn{3}{|c|}{ Atorvastatin } & \multicolumn{3}{c|}{ Amlodipine besylate } \\
\hline $\begin{array}{c}\text { Conc } \\
(\boldsymbol{\mu g} / \mathbf{m l})\end{array}$ & $\mathbf{R}_{\mathbf{t}}(\mathbf{m i n})$ & Peak area & $\begin{array}{c}\text { Conc } \\
(\boldsymbol{\mu g} / \mathbf{m l})\end{array}$ & $\mathbf{R}_{\mathbf{t}}(\mathbf{m i n})$ & Peak area \\
\hline 100 & 6.887 & 11851536 & 50 & 8.573 & 3526567 \\
\hline 200 & 6.843 & 21208649 & 100 & 8.564 & 6456752 \\
\hline 300 & 6.840 & 31405345 & 150 & 8.623 & 9914383 \\
\hline 400 & 6.836 & 41608563 & 200 & 8.721 & 124892352 \\
\hline 500 & 6.423 & 51779928 & 250 & 8.873 & 16238675 \\
\hline
\end{tabular}

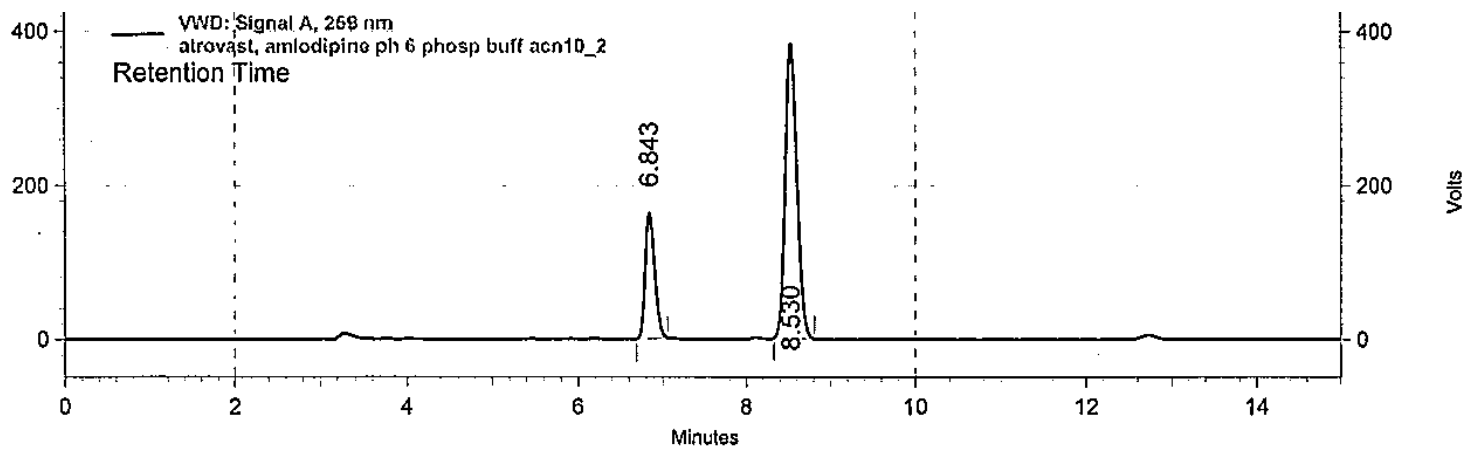

Fig. 3: RP-HPLC Chromatogram of accuracy for the combination

Table 2: Determination of Accuracy for Atorvastatin and Amlodipine besylate by RP-HPLC Method

\begin{tabular}{|c|c|c|c|c|c|c|c|c|c|}
\hline \multirow{3}{*}{ S.No } & \multirow{3}{*}{$\begin{array}{c}\text { Recove } \\
\text { ry } \\
\text { Level }\end{array}$} & \multicolumn{4}{|c|}{ Atorvastatin(10mg) } & \multicolumn{4}{|c|}{ Amlodipine besylate (5mg) } \\
\hline & & \multicolumn{2}{|c|}{$\begin{array}{c}\text { Amount } \\
\text { Added } \\
(\mu \mathrm{g} / \mathrm{ml})\end{array}$} & \multirow{2}{*}{$\begin{array}{l}\text { Amount } \\
\text { Found } \\
\text { (mg) }\end{array}$} & \multirow{2}{*}{$\begin{array}{c}\% \\
\text { Recovery }\end{array}$} & \multicolumn{2}{|c|}{$\begin{array}{c}\text { Amount } \\
\text { Added } \\
(\mu \mathrm{g} / \mathrm{ml})\end{array}$} & \multirow{2}{*}{$\begin{array}{c}\text { Amount } \\
\text { Found (mg) }\end{array}$} & \multirow{2}{*}{$\begin{array}{c}\% \\
\text { Recovery } \\
(w / w)\end{array}$} \\
\hline & & Std & Test & & & Std & Test & & \\
\hline 1 & $80 \%$ & 300 & 100 & 299.28 & 99.76 & 150 & 50 & 149.32 & 98.8 \\
\hline 2 & $100 \%$ & 300 & 200 & 197 & 99.65 & 150 & 100 & 197.23 & 99.6 \\
\hline 3 & $120 \%$ & 300 & 300 & 602.20 & 101.18 & 150 & 150 & 302.21 & 101.1 \\
\hline
\end{tabular}




\section{Indo Global Journal of Pharmaceutical Sciences, 2020; 10(1): 79-84}

\section{Accuracy}

To confirm the accuracy of the proposed method, recovery experiments were performed by standard addition technique. In this method a known quantity of pure drug was added at three different levels i.e. $80 \%, 100 \%$ and $120 \%$ to preanalyzed sample solutions and calculated the recovery of Atorvastatin and Amlodipine besylate for each concentration. Chromatograms showing different levels of recovery were shown in figure 3 . The results of recovery studies by proposed method were validated by statistical evaluation and were given in table 2.

\section{Precision}

The precision of an analytical method was studied by performing intraday and inter day precision. It was determined by analyzing a set of six combined standard solutions of Atorvastatin $(500 \mu \mathrm{g} / \mathrm{ml})$ and Amlodipine besylate $(250 \mu \mathrm{g} / \mathrm{ml})$ in linearity range as $100 \%$ concentration at three different time intervals on same day. Chromatogram representing intraday precision was shown in figure 4 and the results were given in table 3.

\section{LOD and LOQ}

The LOD and LOQ values were determined by the formulae $\mathrm{LOD}=3.3 \sigma / \mathrm{S}$ and LOQ $=10 \sigma / \mathrm{S}$ (Where, $\sigma$ is the standard deviation of the responses and $\mathrm{S}$ is mean of the slopes of the calibration curves). The results were given in table 3.

\section{Robustness}

The solution containing $500 \mu \mathrm{g} / \mathrm{ml}$ of Atorvastatin and 50 $\mu \mathrm{g} / \mathrm{ml}$ of , Amlodipine besylate was injected into sample injector of HPLC three times under different parameters like deliberate variations in flow rate $( \pm 0.2 \mathrm{ml} / \mathrm{min})$ and detection wavelength $( \pm 2 \mathrm{~nm})$. Change in flow rate and the results were given in table 3 . Change in detection wavelength and the results were given in table 3 .

\section{Ruggedness}

The solution containing $50 \mu \mathrm{g} / \mathrm{ml}$ of Atorvastatin and $50 \mu \mathrm{g} / \mathrm{ml}$ of Amlodipine besylate was injected into HPLC three times under different parameters like different analysts. The results were given in table 3 .

Table 3: Validation parameters for Atorvastatin and Amlodipine besylate

\begin{tabular}{|c|c|c|}
\hline \multirow[b]{2}{*}{ Parameter } & \multicolumn{2}{|c|}{ Results } \\
\hline & Atorvastatin & $\begin{array}{c}\text { Amlodipine } \\
\text { besylate }\end{array}$ \\
\hline $\mathrm{R}_{\mathrm{t}}(\min )$ & 6.845 & 8.670 \\
\hline $\begin{array}{l}\text { Beer's Law Range } \\
(\mu \mathrm{g} / \mathrm{ml})\end{array}$ & $100-500$ & $50-250$ \\
\hline $\operatorname{LOD}(\mu \mathrm{g} / \mathrm{ml})$ & 0.658 & 0.544 \\
\hline $\mathrm{LOQ}(\mu \mathrm{g} / \mathrm{ml})$ & 1.99 & 1.64 \\
\hline Assay (\% purity) w/w & 99.8 & 101 \\
\hline \multicolumn{3}{|c|}{ Precision (\%RSD) } \\
\hline Intraday Precision & 0.58 & 0.77 \\
\hline Interday Precision & 0.62 & 0.8 \\
\hline \multicolumn{3}{|c|}{ Robustness (\%RSD) } \\
\hline Flow Rate $0.6 \mathrm{ml} / \mathrm{min}$ & 0.54 & 1.01 \\
\hline Flow Rate $1.0 \mathrm{ml} / \mathrm{min}$ & 0.82 & 0.34 \\
\hline $\begin{array}{l}\text { Detection Wavelength at } \\
257 \mathrm{~nm}\end{array}$ & 0.60 & 0.18 \\
\hline $\begin{array}{c}\text { Detection Wavelength at } \\
261 \mathrm{~nm}\end{array}$ & 0.32 & 0.75 \\
\hline \multicolumn{3}{|c|}{ Ruggedness (\% RSD) } \\
\hline Analyst 1 & 0.62 & 0.41 \\
\hline Analyst 2 & 0.62 & 0.62 \\
\hline
\end{tabular}

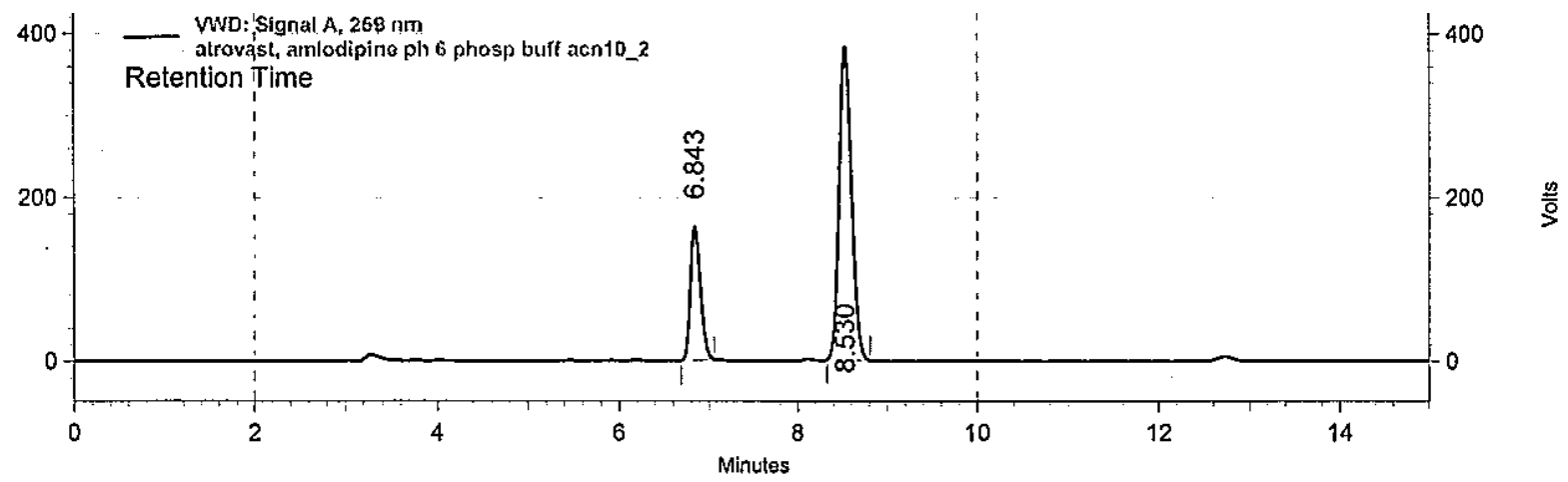

Fig. 4: RP-HPLC Chromatogram of Precision for the combination 


\section{Indo Global Journal of Pharmaceutical Sciences, 2020; 10(1): 79-84}

\section{System Suitability}

The system suitability parameters were evaluated from standard chromatograms by calculating the \% RSD from six replicate injections for Atorvastatin and Amlodipine besylate retention times and peak areas. In this, sample having $500 \mu \mathrm{g} / \mathrm{ml}$ of Atorvastatin and $250 \mu \mathrm{g} / \mathrm{ml}$ of Amlodipine Besylate was injected into the HPLC system. The tailing factor $(\mathrm{T})$ and no. of theoretical plates $(\mathrm{N})$ obtained were shown in results were given in table 4.

\section{Specificity and Selectivity}

The specificity of the RP-HPLC method was determined by complete separation of Atorvastatin and Amlodipine besylate with parameters like retention time (Rt), resolution (Rs) and tailing factor $\left(\mathrm{T}_{\mathrm{f}}\right)$. Here tailing factor for peaks of Atorvastatin and Amlodipine besylate was less than 2\% and resolution was also more than $2 \%$. The average retention time and standard deviation for Atorvastatin and Amlodipine besylate were found to be satisfactory for six determinations of sample solution containing $500 \mu \mathrm{g} / \mathrm{ml}$ of Atorvastatin and $250 \mu \mathrm{g} / \mathrm{ml}$ of, Amlodipine besylate. The peaks obtained for Atorvastatin and Amlodipine besylate were sharp and have clear baseline separation as none of the excipients interfered with the analytes of interest. The results were given in table 4 .

Table 4: Specificity parameters for Atorvastatin and Amlodipine besylate

\begin{tabular}{|c|c|c|}
\hline Parameters & Atorvastatin & $\begin{array}{c}\text { Amlodipine } \\
\text { besylate }\end{array}$ \\
\hline $\begin{array}{c}\text { Retention Time } \\
(\mathrm{min})\end{array}$ & 6.845 & 8.6708 \\
\hline Resolution $\left(\mathrm{R}_{\mathrm{s}}\right)$ & \multicolumn{2}{|c|}{1.687} \\
\hline Tailing Factor $(\mathrm{T})$ & 1.3 & 1.12 \\
\hline $\begin{array}{c}\text { Theoretical Plates } \\
(\mathrm{N})\end{array}$ & 7251 & 11230 \\
\hline
\end{tabular}

\section{Stability studies}

The stability studies were performed as per the ICH guidelines. The samples were stressed under the influence of acid (1N HCL), base $(1 \mathrm{~N} \mathrm{NaOH})$, peroxide (3\% Hydrogen peroxide), UV $(254 \mathrm{~nm})$ and thermal $\left(60^{\circ} \mathrm{C}\right)$ stress for 48 hours. $10 \mathrm{mg}$ of the drug sample was weighed and added to respective condition in an $10 \mathrm{~mL}$ volumetric flask for $48 \mathrm{~h}$. After the stipulated time, the samples of acid and base stress were neutralized to $\mathrm{pH} 7$ and used for analysis. Whereas the other stress samples were diluted to the mark without any neutralization. The concentration of the stress samples were made accordingly to the linearity range and analyzed using the validated HPLC method to identify the stability of samples. The base stress sample chromatogram was shown in figure 5 .

\section{RESULTS AND DISCUSSION}

An optimum mobile phase composition was identified to elute the drugs. The mobile phase ratio and flow rate were selected based on peak parameters (height, capacity, theoretical plates, tailing or symmetry factor), run time and resolution. The system with Phosphate buffer (pH7): Acetonitrile (50:50) and $0.8 \mathrm{ml} / \mathrm{min}$ flow rate was selected. The optimum wavelength selected was $259 \mathrm{~nm}$ from the spectra at which better detector response for the drug was obtained. The retention time for Atorvastatin and Amlodipine besylate was found to be 2.28 $\mathrm{min}$ and $4.85 \mathrm{~min}$ respectively. The linearity was observed in concentration range of $100-500 \mu \mathrm{g} / \mathrm{ml}$ and $50-250 \mu \mathrm{g} / \mathrm{ml}$ for both Atorvastatin and, Amlodipine Besylate.System suitability was assessed by injecting 6 replicate injections of $100 \%$ test concentration. Number of theoretical plates was more than 2000 for both the drugs and tailing factor was less than 1.5 for both Atorvastatin and Amlodipine besylate was reported. A Resolution of greater than 2 was observed. Percentage recoveries of Atorvastatin and Amlodipine besylate were in the range of $99.6-100.3$ and $99.93-100.8$ respectively. Specificity of the chromatographic method was tested by injecting sample concentration prepared from marketed formulation. The response was compared with that obtained from the standard drug. The chromatogram confirms the presence of Atorvastatin and Amlodipine besylate at $6.84 \mathrm{~min}$ and $8.67 \mathrm{~min}$ respectively without any interference. Thus the developed method was specific to Atorvastatin and Amlodipine Besylate.

The robustness of an analytical method was determined by analysis of aliquots from homogenous lots by differing physical parameters such as change in flow rate to $1 \pm 0.2 \mathrm{ml}$ and changing detection wavelength $259 \mathrm{~nm} \pm 2 \mathrm{~nm}$. These values with low $\%$ RSD $(<2)$ indicated that the method was quite robust. Ruggedness of the proposed method was determined by analysis of aliquots from homogeneous slot by different analysts, using similar operational and environmental conditions, the \% RSD reported was found to be less than 2 . The proposed method was validated in accordance with ICH parameters and was applied for analysis of the same in marketed formulations. The content of each component in the formulation was estimated by comparing the peak area of the test sample with that of the peak area of the standard and the results were found to be $99.8 \% \mathrm{w} / \mathrm{w}$ for Atorvastatin and $101 \% \mathrm{w} / \mathrm{w}$ for Amlodipine besylate respectively. 


\section{Indo Global Journal of Pharmaceutical Sciences, 2020; 10(1): 79-84}

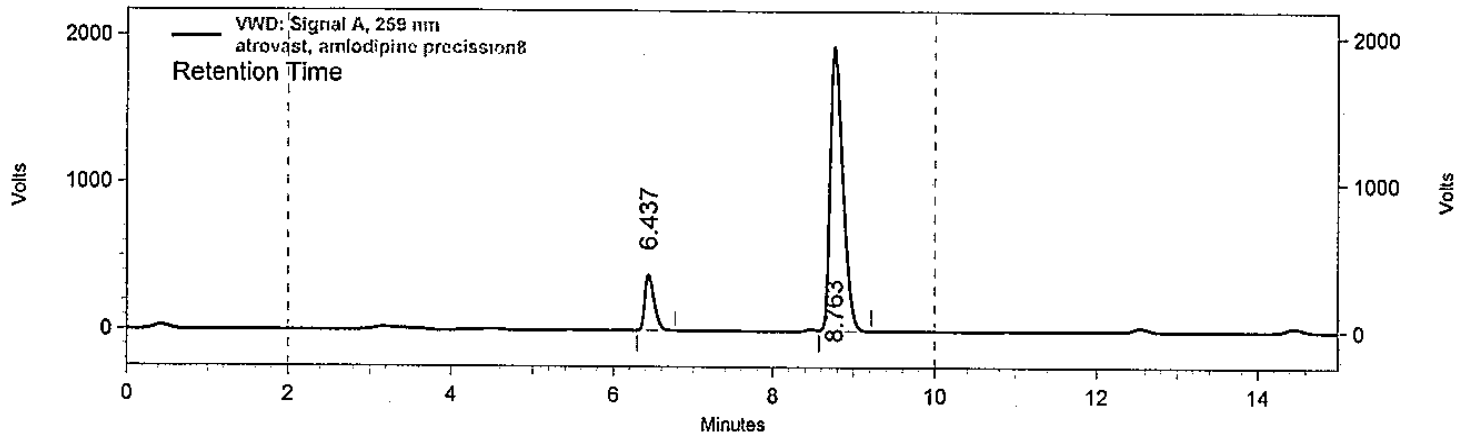

Fig. 5 : RP-HPLC Chromatogram of Base stress sample.

High \% recovery and low \% RSD suggested that the method can be applicable for the routine analysis of commercial formulations.

The stability samples obtained from various stress conditions are passed through the column and observed that no abnormal extra peaks were formed during the conditions, indicating the stability of samples. However little solvent noise was observed in stress samples, which may be due to the conditioned atmosphere interference.

In the present work, an attempt was made to provide a simple and low cost Stability indicating RP HPLC method for the effective quantitative determination of Atorvastatin and Amlodipine besylate in pharmaceutical preparations in their combined dosage forms, without the interferences of other constituent in combined formulations.

\section{CONCLUSION}

The developed stability indicating RP-HPLC method was validated according to ICH guidelines and could be used in routine analysis of Atorvastatin and Amlodipine besylate in their single and combined dosage forms. The method was economical due to less use of mobile phase and less run time. This may allow the analysis of a large number of samples in a short span of time. This method included the stability analysis of samples, where any degradation of products could be easily detected. Hence above method can be used in quality control for routine analysis of finished products of Atorvastatin and Amlodipine besylate simultaneously without any interference.

\section{ACKNOWLEDGEMENT}

The authors are thankful to AG \& SG Degree College and SV University, Tirupati for helping in the completion of project.

\section{DATA AVAILABILITY}

Not Declared.

\section{CONFLICT OF INTEREST}

The authors have no conflicts of interest.

\section{SOURCES OF FUNDING}

No external funding declared.

\section{REFERENCES}

1. Indian Pharmacopoeia, ,2007,2:132,97.

2. Kailash P. et.al. Spectroscopic Method For Estimation of Atorvastatin Calcium in Tablet Dosage Form. Indo Global J Pharm Sci., 2011; 1(4): 294-299.

3. Andreea loredana vonica-gligor. et.al. simultaneous quantification of atorvastatin and Amlodipine in powder blends for tableting by NIR Spectroscopy and chemometry., Farmacia., 2015; 63(3):381-387.

4. Bahia A.Moussa. et. Al. Simultaneous Determination of Amlodipine Besylate and Atorvastatin Calcium in Binary Mixture by Spectrofluorimetry and HPLC Coupled with Fluorescence Detection. Anal Chem Insights.,2013; 8: 107-115

5. Mustafa Çelebier. et.al. HPLC method development for the simultaneous analysis of amlodipine and valsartan in combined dosage forms and in vitro dissolution studies. Brazilian J Pharm Sci., 2010; 46(4):761-768.

6. Nataraj K.S. et.al. Analytical method development and validation of simultaneous estimation of amlodipine besylate and atorvastatin calcium by RP-HPLC method. J Chem Pharm Res, 2015; 7(4):35-41.

7. Mohammadi A.et.al. A stability-indicating high performance liquid chromatographic (HPLC) assay for the simultaneous determination of atorvastatin and amlodipine in commercial tablets. J Chromatogra B., 2007; 42(1): 242-235.

8. Hafez H.M. et.al. Development of a Stability-Indicating HPLC Method for Simultaneous Determination of Amlodipine Besylate and Atorvastatin Calcium in Tablets. Austin J Anal Pharm Chem., 2014; 1(6): 139-145

9. Zahid Zaheer.et.al. Stability-indicating high performance liquid chromatographic determination of Atorvastatin calcium in pharmaceutical dosage form. African J Pharm Pharmacol., 2008; 2(10): 204-210.

10. .Kolsure A.K. et.al. Development and Validation of a HPTLC Method for Simultaneous Estimation of Atorvastatin calcium and Losartan Potassium in Combined Dosage Form. J Med Pharm Inno., 2014; 4 (32). 